\title{
Analysis of frequency and intensity of European winter storm events from a multi-model perspective, at synoptic and regional scales
}

\author{
Gregor C. Leckebusch ${ }^{1, *}$, Brigitte Koffi ${ }^{2}$, Uwe Ulbrich ${ }^{1}$, Joaquim G. Pinto ${ }^{3}$, \\ Thomas Spangehl ${ }^{1}$, Stefan Zacharias ${ }^{3}$ \\ ${ }^{1}$ Institute for Meteorology, Freie Universität Berlin, Carl-Heinrich-Becker-Weg 6-10, 12165 Berlin, Germany \\ ${ }^{2}$ Department of Geosciences, University of Fribourg, Chemin du Musee 4, C1700 Fribourg, Switzerland \\ ${ }^{3}$ Institute for Geophysics and Meteorology, University of Cologne, Kerpener Str. 13, 50937 Köln, Germany
}

\begin{abstract}
This study focuses on the analysis of winter (October-November-December-JanuaryFebruary-March; ONDJFM) storm events and their changes due to increased anthropogenic greenhouse gas concentrations over Europe. In order to assess uncertainties that are due to model formulation, 4 regional climate models (RCMs) with 5 high resolution experiments, and 4 global general circulation models (GCMs) are considered. Firstly, cyclone systems as synoptic scale processes in winter are investigated, as they are a principal cause of the occurrence of extreme, damage-causing wind speeds. This is achieved by use of an objective cyclone identification and tracking algorithm applied to GCMs. Secondly, changes in extreme near-surface wind speeds are analysed. Based on percentile thresholds, the studied extreme wind speed indices allow a consistent analysis over Europe that takes systematic deviations of the models into account. Relative changes in both intensity and frequency of extreme winds and their related uncertainties are assessed and related to changing patterns of extreme cyclones. A common feature of all investigated GCMs is a reduced track density over central Europe under climate change conditions, if all systems are considered. If only extreme (i.e. the strongest $5 \%$ ) cyclones are taken into account, an increasing cyclone activity for western parts of central Europe is apparent; however, the climate change signal reveals a reduced spatial coherency when compared to all systems, which exposes partially contrary results. With respect to extreme wind speeds, significant positive changes in intensity and frequency are obtained over at least 3 and $20 \%$ of the European domain under study $\left(35-72^{\circ} \mathrm{N}\right.$ and $\left.15^{\circ} \mathrm{W}-43^{\circ} \mathrm{E}\right)$, respectively. Location and extension of the affected areas (up to 60 and $50 \%$ of the domain for intensity and frequency, respectively), as well as levels of changes (up to +15 and $+200 \%$ for intensity and frequency, respectively) are shown to be highly dependent on the driving GCM, whereas differences between RCMs when driven by the same GCM are relatively small.
\end{abstract}

KEYWORDS: European winter storms $\cdot$ Extra-tropical cyclones $\cdot$ Extreme wind speeds $\cdot$ Climate change $\cdot$ Global climate models $\cdot$ Regional climate modelling

\section{INTRODUCTION}

Besides flooding (e.g. River Elbe in 2002, River Oder in 1997) and the recent heat wave in boreal summer 2003, winter storms are the most relevant meteorological-hydrological extreme events for central Europe (Cornford 2002, Ulbrich et al. 2003a, 2003b, Fink et al. 2004, Meehl \& Tebaldi 2004). Extreme meteorological conditions lead to e.g. extraordinary high wind speeds, related wave heights, or intense precipitation, generating severe impacts on human facilities and infrastructure, and thus on general socio-economic conditions. The MICE project aims to increase understanding of climate change and its impact on society by generating concrete scientific information that can be used for impact studies, thus assisting with a transfer 
of knowledge from the scientific community to decision-makers.

In this context, it is of crucial importance to gain information on to what extent central European storms and corresponding wind patterns will change under future climate conditions. Will we face more frequent or more intense extreme extra-tropical winter storms? It is still uncertain whether the intensity or frequency of recent extra-tropical cyclones (ETC) underlie a specific long-term trend. There is some evidence from observational data that activity has increased since the 1960s, even though natural inter-decadal variability cannot be ruled out (e.g. Lambert 1996, Serreze et al. 1997, Jones et al. 1999, McCabe et al. 2001, Paciorek et al. 2002, Geng \& Sugi 2003). Additionally, there seems to be different trends in the Northern and Southern Hemispheres, the latter experiencing decreasing cyclone activity since the beginning of the 1990s (e.g. Simmonds \& Keay 2000). Thus, it seems reasonable to investigate the potential future occurrence of ETCs, and their related wind fields, by means of global and regional climate modelling.

While most authors have concentrated their studies on the diagnosis of ETCs for one specific model (e.g. Lunkeit et al. 1996, Carnell \& Senior 1998, Kharin \& Zwiers 2000, Knippertz et al. 2000, Leckebusch \& Ulbrich 2004), with partially different investigation methods, in this study a multi-model approach applying the same investigation method is performed. Additionally, the investigation includes the analysis of ETC related simulated wind speeds from GCMs and RCMs. Consequently, several different regional model simulations are taken into account. Due to the nature of climate models, which have insufficient spatial and temporal resolutions for regional analyses, this study is organized into 3 sequential steps: (1) cyclones are investigated as a causal mechanism and as a scaled phenomena of GCMs; (2) wind speeds are analysed by dynamical downscaling; (3) connections between wind speeds and cyclones are diagnosed.

Potential changes in the frequency and intensity of extreme wind speeds between the latter 20th (1961-1990) and 21st (2071-2100) centuries are investigated on the basis of regional climate simulations of daily maximum wind speeds at $10 \mathrm{~m}$ altitude (hereafter w10max). In order to quantify the confidence and uncertainties in future predictions, we investigated 5 simulations of the SRES-A2 greenhouse gas emissions scenario (SRES: Special Report on Emission Scenarios, Nakićenović et al. 2000), performed in the framework of the PRUDENCE project (Prediction of Regional scenarios and Uncertainties for Defining EuropeaN Climate change risks and Effects, Christensen et al. 2002; see http://prudence.dmi.dk), which were also partly used in the MICE project.
The applied cyclone identification and tracking algorithm is presented in Section 2, in addition to a description of the model chains and of the observational time series used for their validation. The second part of Section 2 is devoted to the discussion on the selection of relevant thresholds and indices to be investigated. Section 3 presents the results, with respect to cyclone systems occurrence and relative changes in terms of intensity and frequency in the occurrence of extreme wind speeds between the present-day and future climates. Section 4 summarizes and discusses the main findings.

\section{DATA AND INVESTIGATION METHODS}

\subsection{Data}

\subsubsection{Model data}

In this study 4 GCMs are analysed: the ECHAM4/ OPYC3 (European Centre Hamburg Version 4/Ocean on isopycnal coordinates 3), ECHAM5/MPI-OM1 (European Centre Hamburg Version 5/Max-Planck-InstituteOcean Model 1), HadAM3P (Hadley Centre Atmospheric Model 3 Version P), and HadCM3 (Hadley Centre Coupled Model 3). With respect to ETC identification and tracking, results were partly published in Leckebusch \& Ulbrich (2004) for HadCM3, and in Pinto et al. $(2005,2006)$ for ECHAM4. Model descriptions and details of included parametrisations can be found in e.g. Roeckner et al. (1999), Gordon et al. (2000), Jones et al. (2001), Hudson \& Jones (2002), Johns et al. (2003), and Roeckner et al. (2003, 2004), and will not be given here. For the identification and tracking of ETCs, mean sea level pressure (MSLP) was used at a daily (HadAM3P, HadCM3), 12-hourly (ECHAM4/OPYC3), and 6-hourly (ECHAM5/MPI-OM1) resolution, respectively. Effects of different time resolutions on cyclone distributions will be discussed in Section 3.

A large set of simulations has been produced within the PRUDENCE project (Christensen et al. 2002) by using a hierarchy of models consisting of 3 coupled atmosphere-ocean GCMs, 4 atmospheric GCMs and 8 nested RCMs with grid meshes ranging from 50 to $20 \mathrm{~km}$ (see http://prudence.dmi.dk/public/description_of_work.pdf for details). Simulations from 4 different model chains, consisting of 3 RCMs and 2 driving GCMs, are considered in this study, in addition to the HadAM3P-HadRM3P simulations produced at the Hadley Centre and used in the framework of the MICE project. They have been selected from a total of 20 PRUDENCE experiments on the basis of analyses conducted by Déqué (2004), in order to cover the range of uncertainties obtained in the predicted 2071-2100 tempera- 
Table 1. MICE ${ }^{1}$ and PRUDENCE ${ }^{2}$ experiments considered in the study of extreme winds. GCM: global climate model RCM: regional climate model. ETHZ: Swiss Federal Institute of Technology, Zurich; SMHI: Swedish Meteorological and Hydrological Institute

\begin{tabular}{|c|c|c|c|c|c|c|}
\hline Institute & RCM model & Driving GCM & Acronym & $\begin{array}{l}\text { Resolution } \\
\quad(\mathrm{km})\end{array}$ & $\begin{array}{l}\text { No. of } \\
\text { grid points }\end{array}$ & $\begin{array}{l}\text { w10max } \\
\text { definition }\end{array}$ \\
\hline Hadley Centre & HadRM3P & HadAM3P & HadRM3P-P ${ }^{1}$ & 50 & 6577 & Max. time step values \\
\hline ETHZ & CHRM & HadAM3H & $\mathrm{CHRM} \mathrm{H}^{2}$ & 55 & 4314 & $\begin{array}{l}\text { Max. time step values } \\
\text { + gust parameter }\end{array}$ \\
\hline SMHI & RCAO & HadAM3H & $\mathrm{RCAO}-\mathrm{H}^{2}$ & $10-70$ & 6226 & Max. time step value \\
\hline
\end{tabular}

ture range (Koffi et al. 2003). They consist of the simulations by the Danish High Resolution Limited Area Model Hamburg Version 4 (HIRHAM4) (Christensen et al. 1998), the Swiss Climate High Resolution Model (CHRM; Lüthi et al. 1996, Vidale et al. 2003) and the Swedish Rossby Centre regional Atmosphere-Ocean model (RCAO) high resolution regional models (Räisänen et al. 2004), driven at their lateral boundaries by HadAM3H (Hudson \& Jones 2002, Johns et al. 2003). Differences between the HadAM3H and HadAM3P versions are primarily restricted to cloud parametrisations, important mainly for tropical regions. For mid-latitude conditions, both versions of the HadAM3 differ only negligibly (R. McDonald pers. comm.). Another RCAO A2 scenario run driven by the ECHAM4/OPYC3 coupled ocean-atmosphere model (Roeckner et al. 1999) is also considered, in order to sample the dependence of results on the driving GCM. Thus, by this comprehensive analysis with a multi-model approach including dynamical downscaling for both investigated GCM families, it should be possible to obtain comparable statements on the variability of ETCs and extreme wind speed occurrence in spite of different model formulations.

The experiments investigated are summarized in Table 1. Suffixes $-\mathrm{H},-\mathrm{P}$ and $-\mathrm{E}$ are used hereafter to denote RCMs driven by the HadAM3H, HadAM3P and ECHAM4/OPYC3 GCMs, respectively. Each daily dataset consists of 6 mo (October to March periods, termed ONDJFM hereafter) with $30 \mathrm{~d}$ per month and two $30 \mathrm{yr}$ periods, i.e. $2 \times 5400$ daily data. The HadRM3P, HIRHAM4, CHRM, and RCAO domains consist of 6577 , 6580,4314 , and 6226 grid points within the studied area $\left(35-72^{\circ} \mathrm{N}, 15^{\circ} \mathrm{W}-43^{\circ} \mathrm{E}\right)$, respectively. For all analysed RCM models, the daily maximum wind speed is defined as the highest value per day produced from all integrated time steps. However, in the case of the CHRM model, a factor accounting for surface near gusts is applied to each time step, using the gust parameterization applied by the German Weather Service (Deutscher Wetterdienst) in its model system (Schrodin 1995).

In order to detect the climate change signal, GCM simulations based on the SRES A2 storyline were used. The A2 storyline and scenario family describes a very heterogeneous world. The underlying theme is selfreliance and preservation of local identities. Fertility patterns across regions converge very slowly, which results in continuously increasing global population. Economic development is primarily regionally-oriented, and per capita economic growth and technological change are more fragmented and slower than in other storylines (Nakićenovic et al. 2000). The signal is detected as the differences between two 30 yr climatological periods. Under the A2 scenario, the time span 2070-2099 is taken as representative for possible future conditions, whereas the years 1960-1989 are identified with present climate conditions ${ }^{1}$. The only exceptions to this are calculations of ETCs for ECHAM4/OPYC3. In this case, two $49 \mathrm{yr}$ episodes of the transient IPCC IS92a scenario were used (control period 1881-1929; scenario period 2040-2088). In the forcing characteristics, both periods are equivalent to the control and scenario period from SRES A2, respectively. Although this is not exactly the same simulation as used for the forcing of dynamical downscaled wind speeds (SRES A2), the basic features of both scenarios are comparable. Thus, from a climatological perspective and with respect to cyclone systems, it seems justified to discuss both simulations equivalently.

It should be noted that for the detection of the climate change signal of wind speed indices, i.e. for the dynamical downscaling, the difference between the A2 scenario period and the control climate simulation, forced by observed sea surface temperatures and sea ice concentrations, was considered.

\subsubsection{Observational data}

Two data sets are used in this study to evaluate the ability of the GCM-RCM model chains in simulating the $10 \mathrm{~m}$-level wind speed and to characterize the

\footnotetext{
${ }^{1}$ This definition applied by the MICE group differs slightly from those used in the PRUDENCE project: control period 1961-1990, scenario period 2071-2100, but this minor difference has no impact on results
} 
indices of extreme winds over the 1961-1990 reference period: (1) daily mean wind speed at $10 \mathrm{~m}$ (hereafter w10m) from the NCEP-NCAR-Re-analysis (Kalnay et al. 1996), and (2) daily observational dataset assembled for France in the framework of the IMFREX project (IMpact des changements anthropiques sur la FRéquence des phénomènes EXtrêmes de vent, de temperature et de precipitation) (see http://medias. dsi.cnrs.fr/imfrex/web/projet/index). The latter dataset is amongst the most consistent daily maximum wind speed datasets presently available in Europe, even though it includes some inhomogeneous time series, i.e. with missing data or artificial breaks during the 1961-1990 period. More details on the effort invested by Météo-France to select and assess w10max time series for the investigation of extreme wind events can be found at http://medias.dsi.cnrs.fr/imfrex/web/projet/ index.fr.php. The observed w10max data are defined (similarly as with the selected RCM simulations) by taking into account all time steps within the day (i.e. from the 144 time steps of 10 min duration), thus allowing their comparison with RCM outputs. Rather than performing a large scale validation, a local illustration of the ability of different RCMs in simulating w10max will be provided by investigating one of the longest available homogeneous w10max time series, namely that of Lille station $\left(50^{\circ} 34^{\prime} \mathrm{N}, 3^{\circ} 06^{\prime} \mathrm{E}\right)$ in northern France, which meets the World Meteorological Organization (WMO) criteria for implantation (B. Dubuisson pers. comm.). In addition, this station is located in a central European region, which should be directly affected by changing ETC behaviour, as demonstrated by Leckebusch \& Ulbrich (2004).

\subsection{Investigation methods}

ETCs were assessed by applying an objective identification algorithm originally published by Murray \& Simmonds (1991), which is organized in 2 steps. Firstly, cyclones are identified by an algorithm based on the search for the maximum of the Laplacian $\left(\nabla^{2} p\right)$ of MSLP. Under quasi-geostrophic conditions, this is equivalent to the search for extremes of relative vorticity. Secondly, a tracking algorithm is applied, which takes into account the most probably shift of the cyclone core under the given circumstances. ETCs were identified for the control and scenario period of each investigated GCM for the winter half-year (ONDJFM). In order to avoid unrealistic artefacts, systems localized in areas with a terrain-height above $1500 \mathrm{~m}$ asl are excluded (due to underground extrapolation of the MSLP). Additionally, open and closed systems are differentiated: a cyclone is determined to be closed if a true minimum of MSLP is situated in the vicinity of a maximum of $\nabla^{2} p$. Furthermore, only systems with a Laplacian $\nabla^{2} p$ above the threshold of $0.1(0.2) \mathrm{hPa}^{\circ} \mathrm{Lat}^{-2}$ for closed (open) systems are considered. If the Laplacian $\nabla^{2} p$ exceeds $0.6 \mathrm{hPa}{ }^{\circ} \mathrm{Lat}^{-2}$, a system is classified as strong; otherwise it is classified as weak. In further considerations, only systems which were at least once in their lifetime closed and strong are included. Thus, the identification details are equivalent to those applied in Leckebusch \& Ulbrich (2004) for HadCM3, assuring comparability of findings in this study. Details of the identification, established tracking algorithm, and current settings of the algorithm and its implications can be found in Murray \& Simmonds (1991), Pinto (2002), Leckebusch \& Ulbrich (2004), and Pinto et al. (2005).

There is no single definition of what constitutes a wind storm event or an extreme wind speed. To emphasize the character of the changes in the intensity and frequency of extreme wind speed, percentile thresholds of the daily maximum wind speed distribution that allow a consistent analysis over Europe and also avoid some of the model discrepancies (see Section 4.1) are used in this paper. Three thresholds (i.e. 90th, 95th and 99th percentiles) are investigated in order to better characterize changes in the upper tail of the w10max probability density function (PDF). They are calculated at each grid point and for each $30 \mathrm{yr}$ period from the $5400(30 \times 180)$ ONDJFM days. The motivation for using a single threshold over the 30 years is to effectively select the highest wind speed values over the climate periods (independent of their absolute values). Indeed, indices based on annual data, such as the commonly used 'annual maximum wind speed', are very meaningful for determining inter-annual variability in the intensity of severe wind events, or to calculate return periods of a given wind speed level. They lead to the selection of an equal number of days per year (e.g. 1 in the case of the annual maximum wind speed; 9 in the case of the annual half-year winter 95th percentile), independent of how extreme these days actually are with reference to the climate period.

Two sets of indices are used to document the occurrence of extreme winds in terms of intensity and frequency, and are defined as follows: intensity indices of extreme winds (referred to as 190th, 195th and I99th, hereafter, for the 90th, 95th and 99th percentile thresholds, respectively) correspond to mean of the w10max daily data above the corresponding thresholds (unit: $\mathrm{m} \mathrm{s}^{-1}$ ). They are calculated from the 540, 270 and 54 highest ONDJFM wind speed values, respectively. Frequency indices of extreme winds (referred to as F90th, F95th and F99th, hereafter, for the 90th, 95th and 99th percentile thresholds, respectively) correspond to the number of days above the 1961-1990 high 
percentiles values (unit: d). They are calculated for future climate by applying the 1961-1990 thresholds to 2071-2100 data, whereas they are equal to 540, 270 and $54 \mathrm{~d}$ at all grid points for the 1961-1990 period.

In both cases, the PDF of these indices are far from Gaussian distributions, a behaviour similar to other climate extreme indicators based on high percentile values (see for instance Peterson et al. 2001, Koffi et al. 2003). Therefore, distribution-free tests have to be used to compare mean indices calculated for the 2 climate periods. The Mann-Whitney $U$-test (unilateral test, $\alpha<2.5 \%$ ) is considered in Section 4 to asses the significance of changes in intensity and frequency indices between the 20th and 21st centuries. In the case of the $I x x^{\text {th }}$ intensity indices, it is applied at each grid point to the $2 \times 540$ (270 and 54) values of the days above 90th (95th and 99th) percentiles. The significance of change in the Fxx ${ }^{\text {th }}$ frequency indices is assessed by applying the 1961-1990 thresholds to annual data, i.e. by comparing the 2 sets of 30 annual counts of extreme days, and so accounting for interannual variability.

\section{RESULTS}

\subsection{Cyclone system analysis}

For HadAM3P, ECHAM4/OPYC3, and ECHAM5/ MPI-OM1 the cyclone track density (unit: systems per $5 \times 5^{\circ}$ Lat. box per winter) is presented in Fig. 1a,c,e, respectively. Similar to results from HadCM3 (Leckebusch \& Ulbrich 2004, their Fig. 1a), HadAM3P exhibits 3 maxima: (1) above the Baffin Bay/Davis Street region, (2) the Artic Ocean just to the south of Svalbard, and (3) above Iceland. Due to improved model physics and a higher spatial resolution of HadAM3P $\left(1.875 \times 1.875^{\circ}\right.$ compared to $2.5 \times 3.75^{\circ}$ Lat./Long. for HadCM3) the maximum number increases from around 36 (HadCM3) to about 44 systems per winter. The track density decreases to a minimum of about 12 systems over central Europe and 4 systems over the Iberian Peninsula. A secondary maximum is identified over the central Mediterranean, which is related to Genoa-cyclogenesis. This general pattern is similar for ECHAM4/OPYC3 and ECHAM5/MPI-OM1 (Figs. 1c,e), with slight differences in the total number of tracked ETCs. Thus, due again to higher horizontal and vertical resolution and improved model physics, ECHAM5/MPIOM1 simulates a maximum of about 48 ETCs, whereas ECHAM4/OPYC3 simulates only about 40 systems. The most remarkable difference between the models is the relative track density minimum over northeast Scandinavia simulated by ECHAM4/ OPYC3.

These results are validated against an ETC-analysis performed for observation near NCEP-Re-analysis MSLP data. Calculations performed in an identical manner as those for GCMs reveal general patterns that are almost similar (cf. Leckebusch \& Ulbrich 2004, their Fig. 1b), with an equal magnitude of identified systems taking the different spatial and temporal resolution into account. More details to changing identified ETC numbers with different resolutions can be found in Pinto et al. (2005). Besides a minimum above northeast Scandinavia (ECHAM4/OPYC3), the models reoduce cyclone characteristics as deduced from NCEP reanalysis data reasonably well. With respect to the scope of this study, which is to concentrate on changes with respect to climate change conditions and, especially, on different patterns for extreme ETCs, it is concluded that all investigated models perform in an adequate way for the North-Atlantic/European region. This supports the statement from the IPCC regarding the general ability of models to simulate ETCs (McAvaney et al. 2001).

For central Europe, the climate change signal for all considered ETCs reveals similarities between HadAM3P and ECHAM5/OM1 regarding generally decreased track density. Changes are negligibly small (cf. Fig. 1b,d,f), and are partly insignificant with respect to a local Student's $t$-test. North of approximately $60^{\circ} \mathrm{N}$ and over the Mediterranean area, significant maximum negative changes occur (over the Norwegian Sea/Arctic Ocean: approximately $-15 \%$; over the Mediterranean: approximately -20\%). ECHAM4/OPYC3 simulates increased track density up to $10 \%$ in a band northwards of $60^{\circ} \mathrm{N}$, and significant negative changes (up to -20\%) over wide parts of central Europe. Over Greenland, positive changes are identified by all models.

In order to identify changes in extreme cyclone systems, we introduce a percentile threshold to separate them from all considered systems. Here we choose the 95th percentile of the strength of the Laplacian $\nabla^{2} p$ of MSLP, i.e. only ETCs that have exceeded this threshold at least once in their lifetime are considered. Thus, only the strongest $5 \%$ of systems are taken into account. It should be noted that this threshold was calculated once for each climatological period, and not for each year separately (cf. Table 2). The climatology of

Table 2. 95th percentile threshold value of Laplacian $\nabla^{2} p$ of mean sea level pressure for control and scenario period for GCMs

\begin{tabular}{|lcccc|}
\hline Period & HadCM3 & HadAM3P & ECHAM4/OPYC3 & ECHAM5/OM1 \\
\hline Control & 2.203 & 1.931 & 2.699 & 2.652 \\
Scenario & 2.177 & 1.899 & 2.732 & 2.650 \\
\hline
\end{tabular}



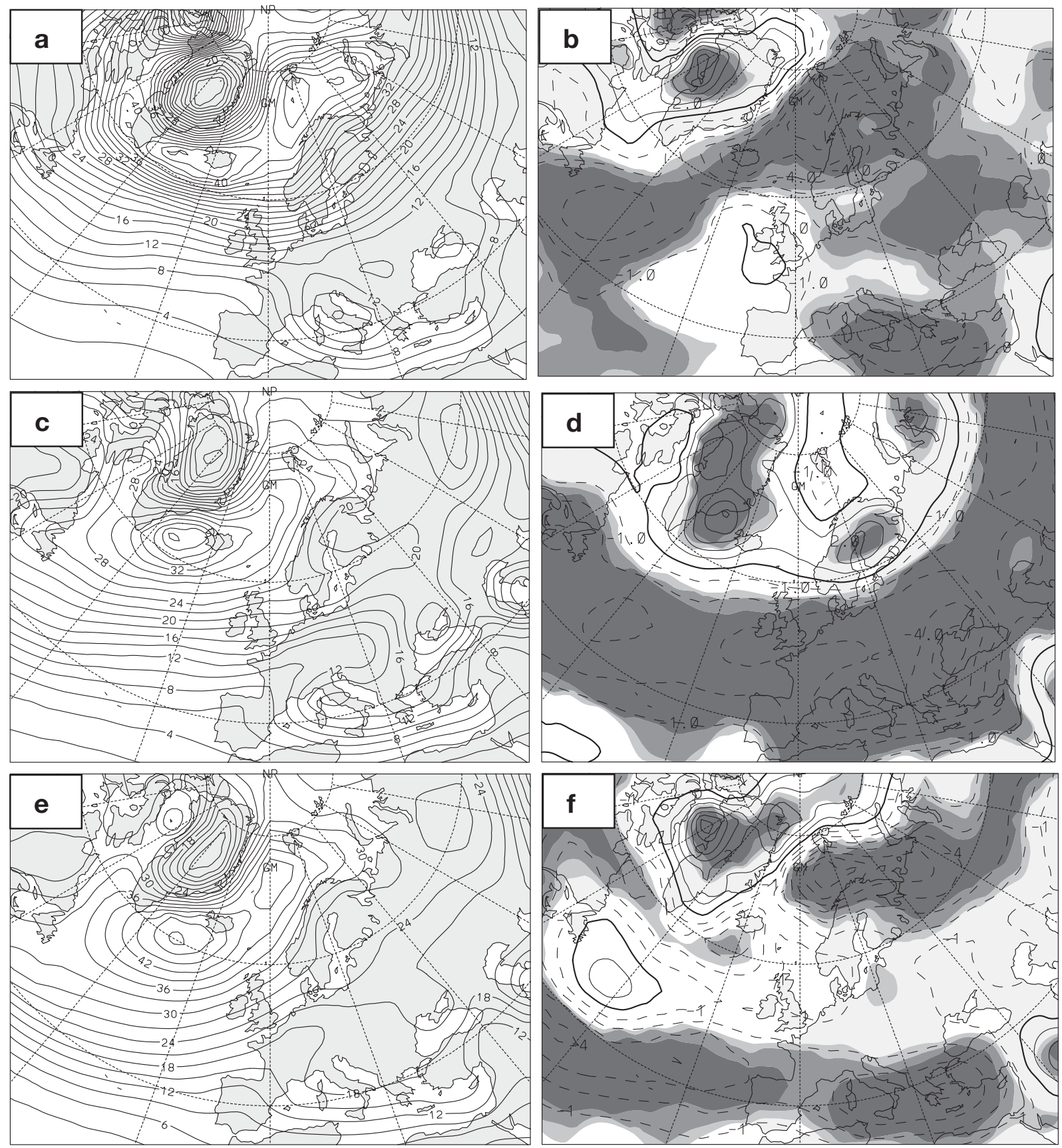

Fig. 1. Cyclone track density (winter: ONDJFM), all systems (unit: no. of systems per $5 \times 5^{\circ}$ Lat. box per winter; negative values are dashed). (a) HadAM3P control period (1960-1989, CON); (b) HadAM3P SRES A2 Climate change signal: (2070-2099) - CON; (c) ECHAM4/OPYC3 control period (1881-1929); (d) ECHAM4/OPYC3 IS92a Climate change signal: (2040-2088) - CON; (e) ECHAM5 control period (1960-1989); (f) ECHAM5 Climate change signal (2070-2099) - CON. Contour interval: (a,c) 2 systems winter $^{-1}$ Lat. $^{-2}$; (e) 3 systems winter ${ }^{-1}$; (b,d,f) 1 system winter ${ }^{-1}$. Areas above 90, 95, $99 \%$ significance level are shaded light, medium and dark grey, respectively (in b, d, and $\mathrm{f}_{i}$ Student's $t$-test)

extreme ETCs reveals a pronounced maximum just southwest of Iceland for all analysed models (cf. Fig. 2a,c,e, and Leckebusch \& Ulbrich 2004, their Fig. 2a), with values of about 7 to 9 systems per winter. Over central Europe, the track density decreases to approximately less than 1 system per winter. In contrast to findings for all systems for extreme systems $\left(\nabla^{2} p>95\right.$ th percentile), different climate change patterns are diagnosed. HadAM3P (Fig. 2b) simulates significant positive changes up to $30 \%$ over the British Islands and 

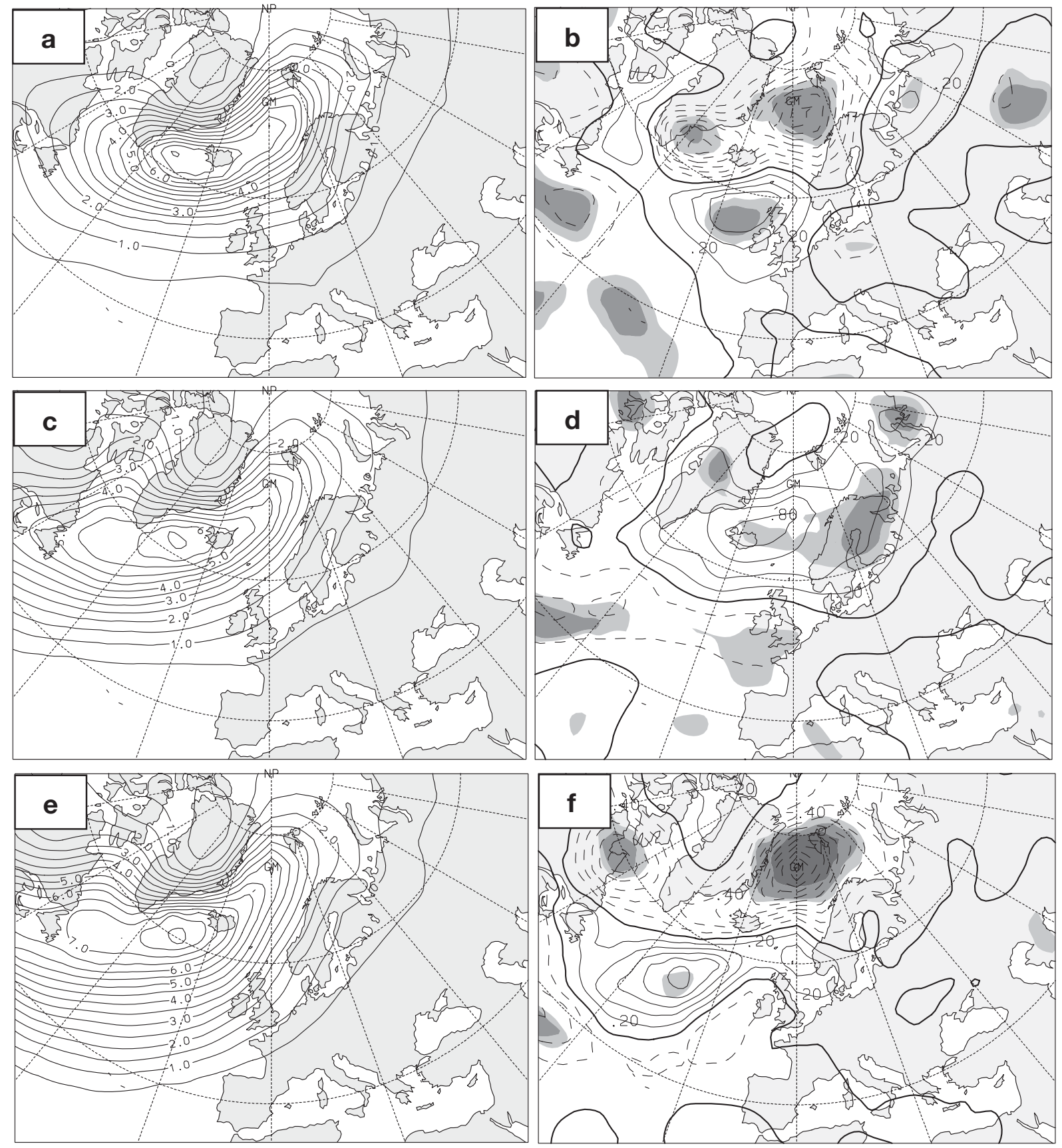

Fig. 2. Cyclone track density (winter: ONDJFM) of only the strongest $5 \%$ of systems, i.e. $\nabla^{2} p>95$ th percentile; negative values are dashed. (a) HadAM3P control period (1960-1989); (b) HadAM3P SRES A2 Climate change signal: (2070-2099) - CON; (c) ECHAM4/OPYC3 control period (1881-1929); (d) ECHAM4/OPYC3 IS92a Climate change signal: (2040-2088) - CON; (e) ECHAM5 control period (1960-1989); (f) ECHAM5 Climate change signal (2070-2099) - CON. Contour interval: (a,c,e) 0.5 systems winter ${ }^{-1}$ Lat. $^{-2} ;(b, d, f) 0.2$ systems winter ${ }^{-1}$. Areas above 90, 95, $99 \%$ significance level are shaded light, medium and dark grey, respectively (in $b, d$, and $f_{i}$ Student's $t$-test)

the adjacent northeast Atlantic, which is similar to results from HadCM3 (Leckebusch \& Ulbrich 2004, their Fig.2b). Negative changes are mainly identified over Iceland and the Norwegian Sea, again in accordance with HadCM3. For central Europe, changes are small.
The pattern observed for ECHAM5/MPI-OM1 is mostly similar; however, maximum positive changes are shifted to the west over the North Atlantic (cf. Fig. 2f), but with slight positive changes still observed over large parts of central Europe. Maximum negative changes are 
again identified over the Norwegian Sea. In contrast, almost opposite patterns are observed for ECHAM4/ OPYC3, with maximum positive changes above Iceland and significant positive changes over northeast Scandinavia. It should be taken into account that in this region, the performance of ECHAM4/OPYC3 is disproportionately inconsistent with NCEP-Re-analysis. Even though the ETC changes for the ECHAM4/OPYC3 simulation differ from others, the diagnosed signatures are consistent with baroclinicity and MSLP changes identified in this simulation (cf. Pinto et al. 2006, Fig. 7). In summary, it should be noted that under anthropogenically changed climate conditions, extreme ETCs behave partly in an opposite manner as all systems do. This is more pronounced for the Hadley Centre models (HadCM3, HadAM3P); the ECHAM-models show non-synchronous climate change patterns.

\subsection{Dynamical downscaled wind speeds}

\subsubsection{Evaluation of simulated 1961-1990 wind speeds}

The high resolution simulations that have been completed for Europe in the framework of the PRUDENCE project have been validated against the University of East Anglia Climate Research Unit (CRU) climatology (New et al. 1999) in order to assess uncertainty in the simulations produced. While uncertainties clearly exist, these were shown to be smaller than average climate- response. For instance, seasonal means of maximum temperature as simulated by RCMs generally show a good agreement with observations, with absolute biases (with reference to CRU data) below $1.5^{\circ} \mathrm{C}$ over most of Europe (e.g. Räisänen et al. 2004).

On the other hand, no validation or evaluation of simulated wind speeds has yet been provided in the framework of PRUDENCE. Although it is beyond the scope of this paper to perform such a validation, we attempt in this section to provide a first assessment of the ability of the regional model experiments to simulate the upper tail of the near surface wind speed at both local and European scales.

For the 99th percentile of daily mean wind speed (w10m) as simulated by the 5 control runs, the distribution over Europe shows comparable results to NCEPNCAR reanalysis (without figure). Although no quantification of uncertainty is performed, Fig. 3 reveals that abilities to reproduce w10m-averaged patterns differ among models: while the HIRHAM model shows the most pronounced discrepancies, the RCAO experiments provide the best agreement when compared to observations, independent of the driving GCM. Nevertheless, with the exception of the HIRHAM4-H simulations, rather realistic 99th percentile wind speeds (which range between 6 and $12 \mathrm{~m} \mathrm{~s}^{-1}$ ) are generally obtained. The influence of land-sea contrasts can be clearly seen, especially for RCAO simulations, i.e. with even more realistic patterns than from re-analysis, thanks to higher spatial resolution (10 times more grid
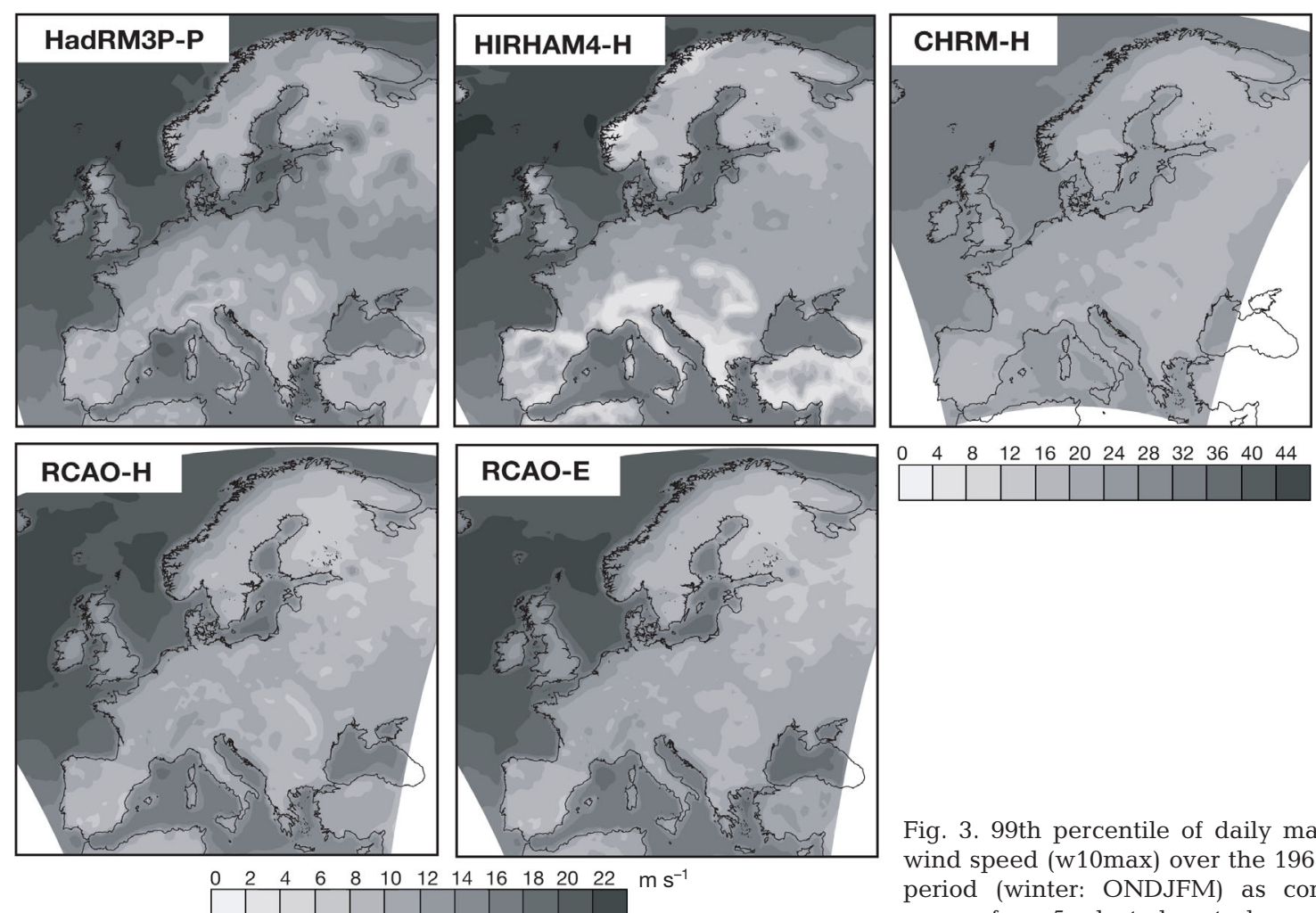

Fig. 3. 99th percentile of daily maximum wind speed (w10max) over the 1961-1990 period (winter: ONDJFM) as computed from 5 selected control runs 
points in comparison to NCEP-Re-analysis) and more details on the spatial patterns via orography influence and surface roughness.

Maps for the 99th percentile of daily maximum wind speeds are provided in Fig. 3. Results reveal similar spatial patterns, but logically higher wind speeds compared to w10m, with the CHRM showing the highest maximum wind speeds over the whole studied domain. As previously mentioned, the w10max is defined in all selected simulations by taking into account all the time steps. Therefore, the strongest winds simulated by the CHRM model compared to the other simulation experiments can clearly be explained by the use of an additional gust parameterization. Nevertheless, no evaluation of the simulated w10max is performed at a European scale due to the lack of an available consistent European-scale dataset of daily maximum wind speed.

To determine how realistic simulated levels of daily maximum wind speed are, a comparison with observations at 1 selected station is provided in Fig. 4. It compares the 1975-1990 PDF's of measured and simulated daily maximum wind speed for Lille station (France, WMO No. $70150,50^{\circ} 34^{\prime} \mathrm{N}, 3^{\circ} 6^{\prime} \mathrm{E}, 52 \mathrm{~m}$ a.s.l.) and the corresponding nearest model grid points (less than $25 \mathrm{~km}$ distance, with a comparable altitude). The observed 90th, 95th and 99th ONDJFM percentiles at this particular station are equal to 14,16 and $21 \mathrm{~m} \mathrm{~s}^{-1}$, respectively. With reference to the Beaufort scale, they roughly refer to 'near gale', 'gale' and 'severe gale' events, respectively. As an illustration, the wind speeds recorded at this station during the well-known storm events that hit Europe in January and February 1990 (e.g. Dorland et al. 1999) are all above the observed 95th (11-12 Feb Nana, 13-14 Feb Otille and 14-15 Feb Polly storms) or 99th (25-26 Jan Daria, 3-4 Feb Hertha, 7-8 Feb Judith, 25-27 Feb Vivian, and 28 Feb-01 Mar Wiebke storms) percentile values. Comparisons with simulations at this particular site shows that the HadRM3P-P, HIRHAM4-H, RCAO-H and RCAO-E experiments underestimate daily maximum wind speed, whereas the gust parameterization used by the CHRM model leads (on average) to significantly higher w10max wind speeds.

Examination of the upper tail of the distributions only, reveals that simulations using a gust parameterization better reproduce the high percentile values of observed wind speeds (Fig. 5). However, this agreement might be partly accidental, i.e. obtained by chance and/or for the wrong reasons. As an illustration of discrepancies that exist between simula-

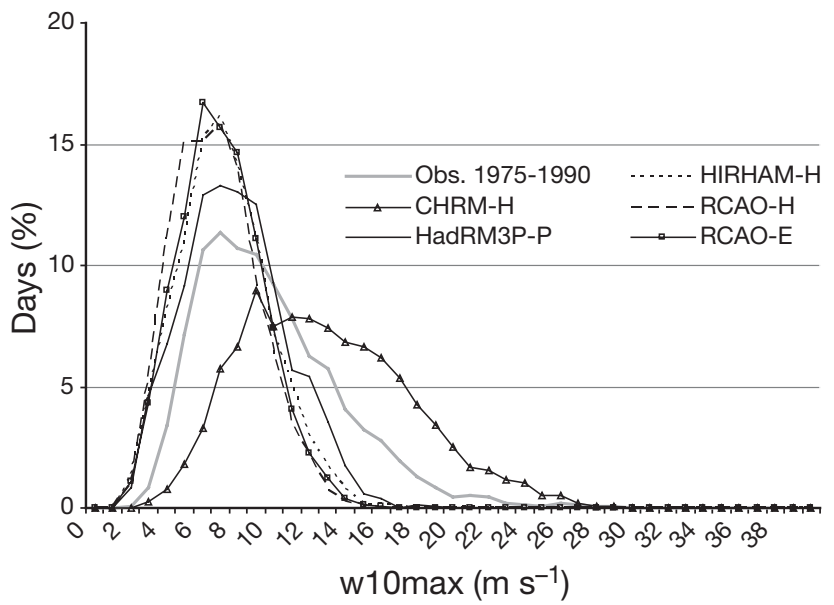

Fig. 4. 1975-1990 probability density functions of measured (obs.) and simulated daily maximum wind speed in winter: (ONDJFM) at Lille station (France) and at nearest grid points

tions and observations, the $20 \mathrm{~m} \mathrm{~s}^{-1}$ threshold is used to define extreme wind events at the Lille station over the 1975-1990 period. Results highlight 34 events from observations, but 5 times more (196) and none or only 1 event(s) from simulations with (CHRM-H) and without (other simulations) gust parameterization, respectively. These results at a local scale are in accordance with Rockel (unpubl. data), who showed that none of the PRUDENCE experiments without wind gust parameterisation allow identification of any storms event in Europe over the 1961-1990 period, when using a fixed threshold of Beaufort $(\mathrm{Bft}) \geq 10\left(\geq 24.5 \mathrm{~m} \mathrm{~s}^{-1}\right)$. On the other hand, the simulation with gust parameterization markedly overestimates the number of extreme events.

This evaluation clearly demonstrates the necessity to use percentile thresholds rather than fixed ones as a definition of wind extreme events from RCM sim-

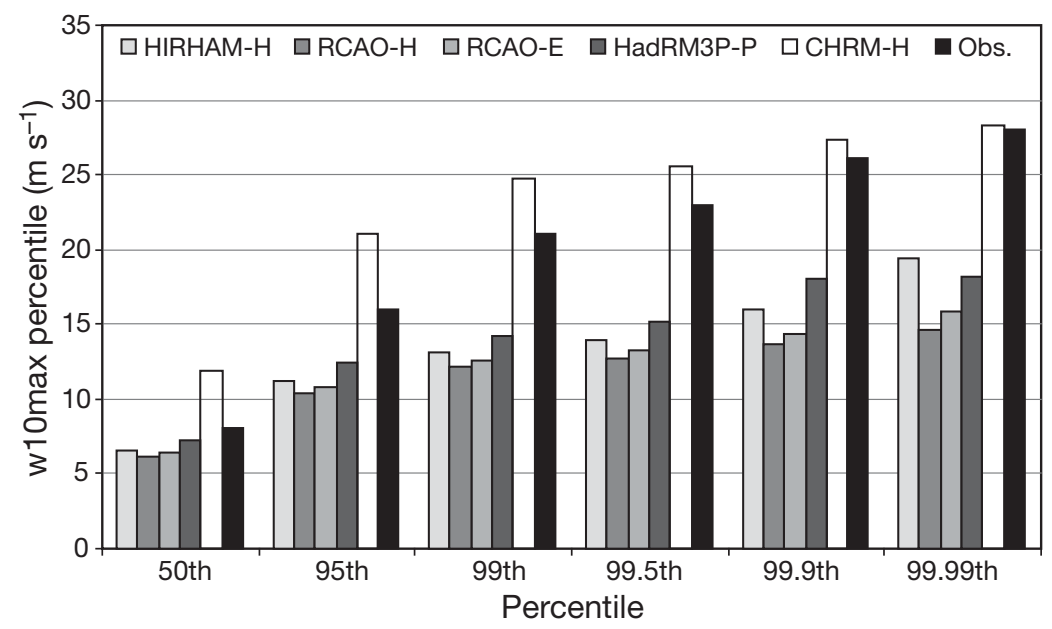

Fig. 5. Percentile values of 1975-1990 probability density functions of measured (obs.) and simulated daily maximum wind speed in winter (ONDJFM) at Lille station (France) and at nearest grid points 
ulation outputs. For the same reason, only relative changes in those percentiles are considered in order to assess changes in the occurrence of wind storms events. Our assumption here is that potential changes in w10max wind speeds should be highly connected to the changes in w10m wind (e.g. Dorland et al. 1999, Jungo et al. 2002), and largely determined by changes in daily mean and maximum surface temperature and pressure patterns. Since these 3 last parameters have been shown to be realistically reproduced over the reference period and for most of Europe by the models under study (e.g. this study, without figure; Beniston et al. unpubl. data, Koffi et al. 2003), it provides a measure of credibility for model projections of relative changes in w10max between the 20th and 21st centuries.

\subsubsection{Changes in intensity of extreme wind speeds}

Fig. 6 presents the relative change in the I99th intensity index as simulated over the studied domain by the 5 model chains between present (1961-1990) and future (2071-2100) climate conditions. Consistent with previous studies (e.g. Leckebusch \& Ulbrich 2004), changes range between approximately $-16 \%$ to $+16 \%$
Table 3. Proportion (\%) of grid points within the studied European domain affected by significant changes (Mann-Whitney unilateral $U$-test, $\alpha<2.5 \%$ ) in intensity of extreme winds (I99th) and frequency (F99th) indices

\begin{tabular}{|c|c|c|c|c|c|}
\hline Change (\%) & HIRHAM-H & CHRM-H & RCAO-H & HadRM3P-P & RCAO-E \\
\hline \multicolumn{6}{|c|}{ I99th intensity index } \\
\hline$<-16$ & 0 & 0 & 0 & 0 & 0 \\
\hline$<-8$ & 1 & 1 & 0 & 1 & 0 \\
\hline$<-4$ & 12 & 12 & 7 & 11 & 5 \\
\hline$<-2$ & 25 & 26 & 20 & 26 & 12 \\
\hline-2 to 0 & 3 & 3 & 5 & 3 & 1 \\
\hline 0 to +2 & 3 & 5 & 4 & 4 & 2 \\
\hline$>+2$ & 22 & 18 & 20 & 18 & 61 \\
\hline$>+4$ & 9 & 5 & 7 & 5 & 47 \\
\hline$>+8$ & 1 & 0 & 0 & 0 & 14 \\
\hline$>+16$ & 0 & 0 & 0 & 0 & 0 \\
\hline All changes & 52 & 51 & 49 & 51 & 77 \\
\hline \multicolumn{6}{|c|}{ F99th frequency index } \\
\hline$<-50$ & 3.4 & 5.6 & 3.0 & 2.8 & 0.7 \\
\hline$<-25$ & 5.4 & 7.9 & 5.5 & 5.2 & 2.3 \\
\hline-25 to 0 & 0 & 0 & 0 & 0 & 0 \\
\hline 0 to +25 & 0 & 0 & 0 & 0 & 0 \\
\hline$>+25$ & 3.1 & 2.8 & 6.3 & 5.9 & 51 \\
\hline$>+50$ & 2.7 & 2.7 & 5.6 & 5.3 & 50 \\
\hline$>+100$ & 0.1 & 0 & 0.4 & 0.4 & 31 \\
\hline$>+150$ & 0 & 0 & 0 & 0 & 12 \\
\hline$>+200$ & 0 & 0 & 0 & 0 & 4 \\
\hline All changes & 8.5 & 11 & 12 & 11 & 53 \\
\hline
\end{tabular}
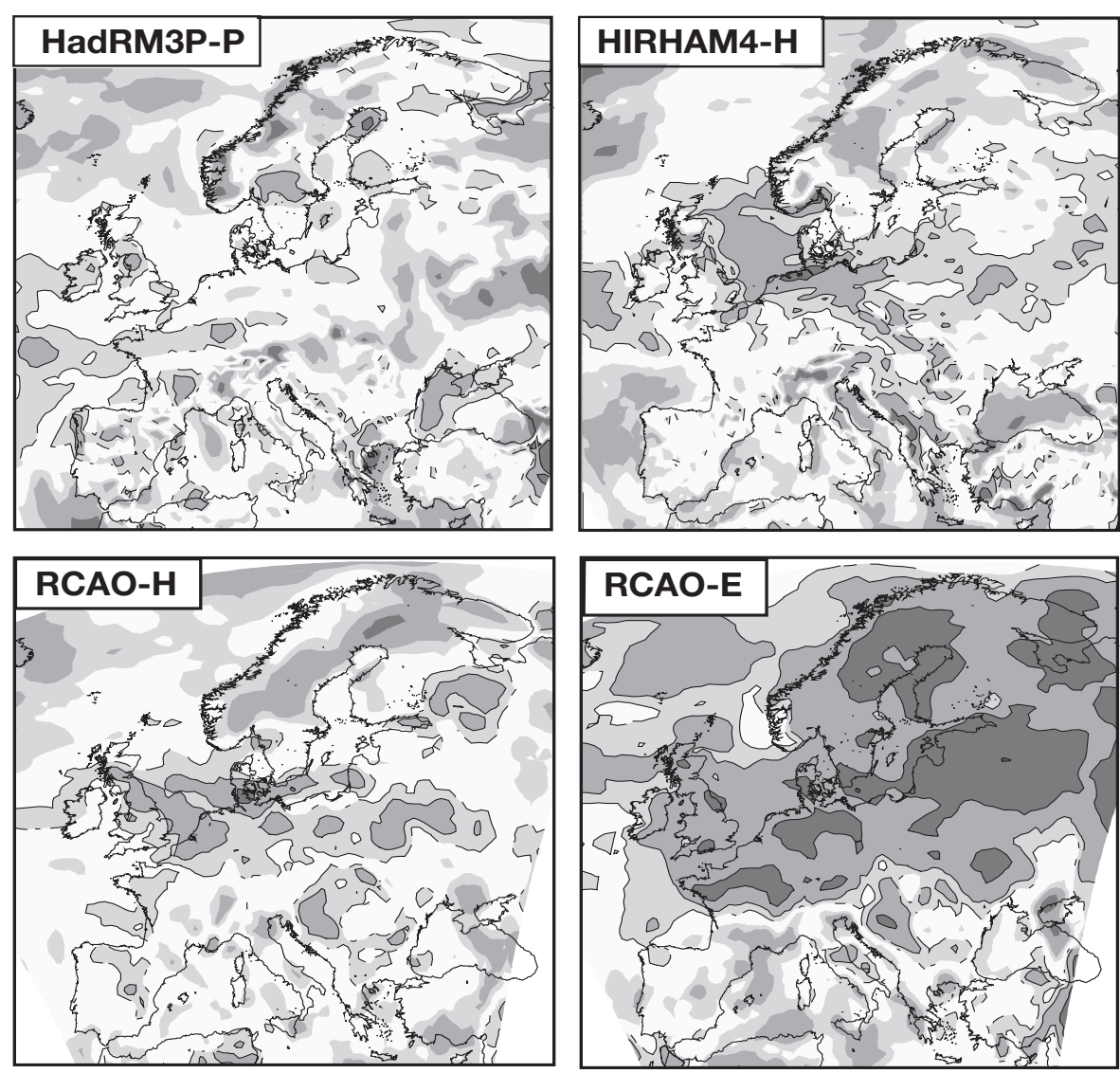
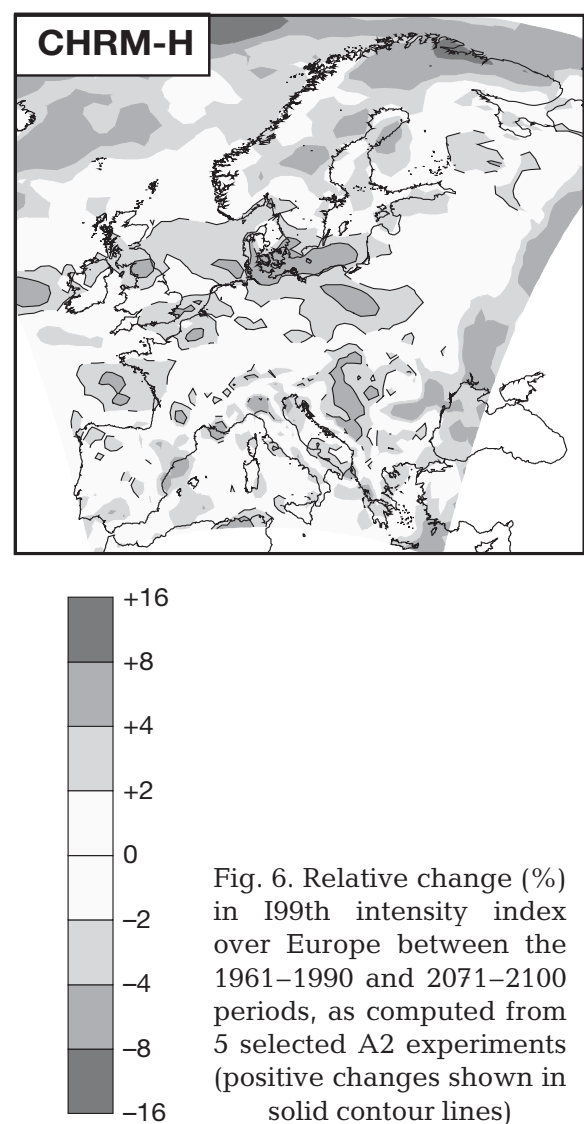

Fig. 6. Relative change (\%) in I99th intensity index over Europe between the 1961-1990 and 2071-2100 periods, as computed from 5 selected A2 experiments (positive changes shown in solid contour lines) 
over the whole continent. Nevertheless, those changes in extreme wind intensity are shown to be statistically significant (Mann-Whitney unilateral $U$-test, $\alpha<$ $2.5 \%$ ) over 49 to 52 and $77 \%$ of the studied area, for the Hadley (HadAM3H and HadAM3P) and ECHAM GCM-driven experiments, respectively (Table 3 ).

Between 84 and $91 \%$ (RCM-H and RCM-P experiments, termed RCM-H/P hereafter) and 97\% (RCM-E experiment) of simulated changes above $+2 \%$ are shown to be statistically significant (against $<18 \%$ for predicted changes ranging between 0 and $+2 \%$ ). Such an increase in the I99th index (in grey areas with contouring lines in Fig. 6) is obtained for 18 to $22 \%$ (RCM-H/P) and $61 \%$ (RCM-E) of the grid points. All RCM-H/P simulations predict the northwestern part of Europe to be the most affected, with the main impact over the British Isles for HIRHAM, CHRM and RCAO models, and over northwest of France in the case of HadRM3P model. The RCAO model driven by ECHAM GCM leads to very different patterns: in that case, the entire northern half of Europe shows a significant increase in intensity of extreme wind speeds, with the highest changes observed around the Baltic Sea. Predicted changes are much more pronounced than those of the RCM$\mathrm{H} / \mathrm{P}$ experiments. As an example, changes above $+4 \%$ are obtained over $47 \%$ of the domain for the RCAO-E but over less than $9 \%$ for all other simulations. It should be stressed that these findings-derived from dynamical downscaling - fit very well to the results presented in the previous section (3.1.), obtained with ETC diagnostics based on GCM simulations. The areas of maximum positive changes with respect to climate change are situated more or less immediately southward of the centres of changing extreme cyclone activity, where enhanced wind speeds would be expected from theoretical considerations.

Simulated changes in the three 190th, 195th and I99th intensity indices are summarized in Fig. 7. Different scales are used to map RCM-H/P and RCM-E predictions, due to large differences in the spatial spread of changes that mainly affect a northwestern portion of Europe, or the entire northern half of Europe, respectively. When looking at increases above 2 and $4 \%$, results from the HadAM3H-driven experiments reveal that the higher the percentile considered, the larger
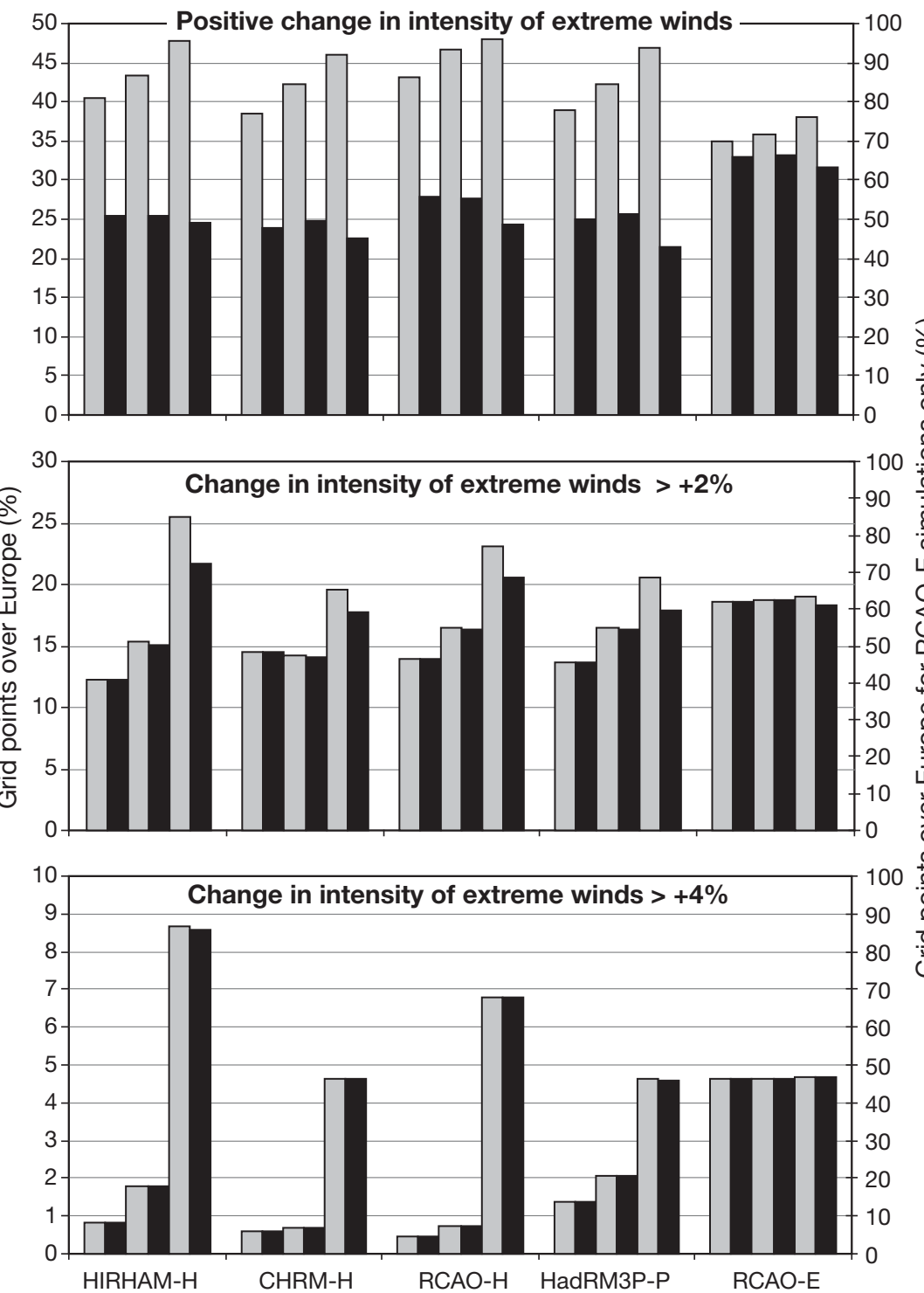

Fig. 7. Proportion (\%) of grid points within the studied European area $\left(35-72^{\circ} \mathrm{N}, 15^{\circ} \mathrm{W}-43^{\circ} \mathrm{E}\right)$ affected by positive changes in (from left to right) I90th, I95th and I99th intensity indices. Grey and black bars correspond to total and significant (Mann-Whitney unilateral $U$-test, $\alpha<2.5 \%$ ) changes, respectively

the area affected and the higher the increase predicted (i.e. change in I90th index < change in 195th index < change in I99th index). This result, in accordance with previous preliminary analyses carried out only on the HIRHAM model (Koffi et al. 2003), implies that the change in extreme wind speed is not explained exclusively by an overall shift in mean, but rather by an additional change in variability of the distribution. A different behaviour is exhibited for the ECHAMdriven simulations that lead to similar increases for the three 190th, 195th and 199th indices. For all studied experiments, similar spatial patterns (but with more pronounced positive significant changes) are simu- 

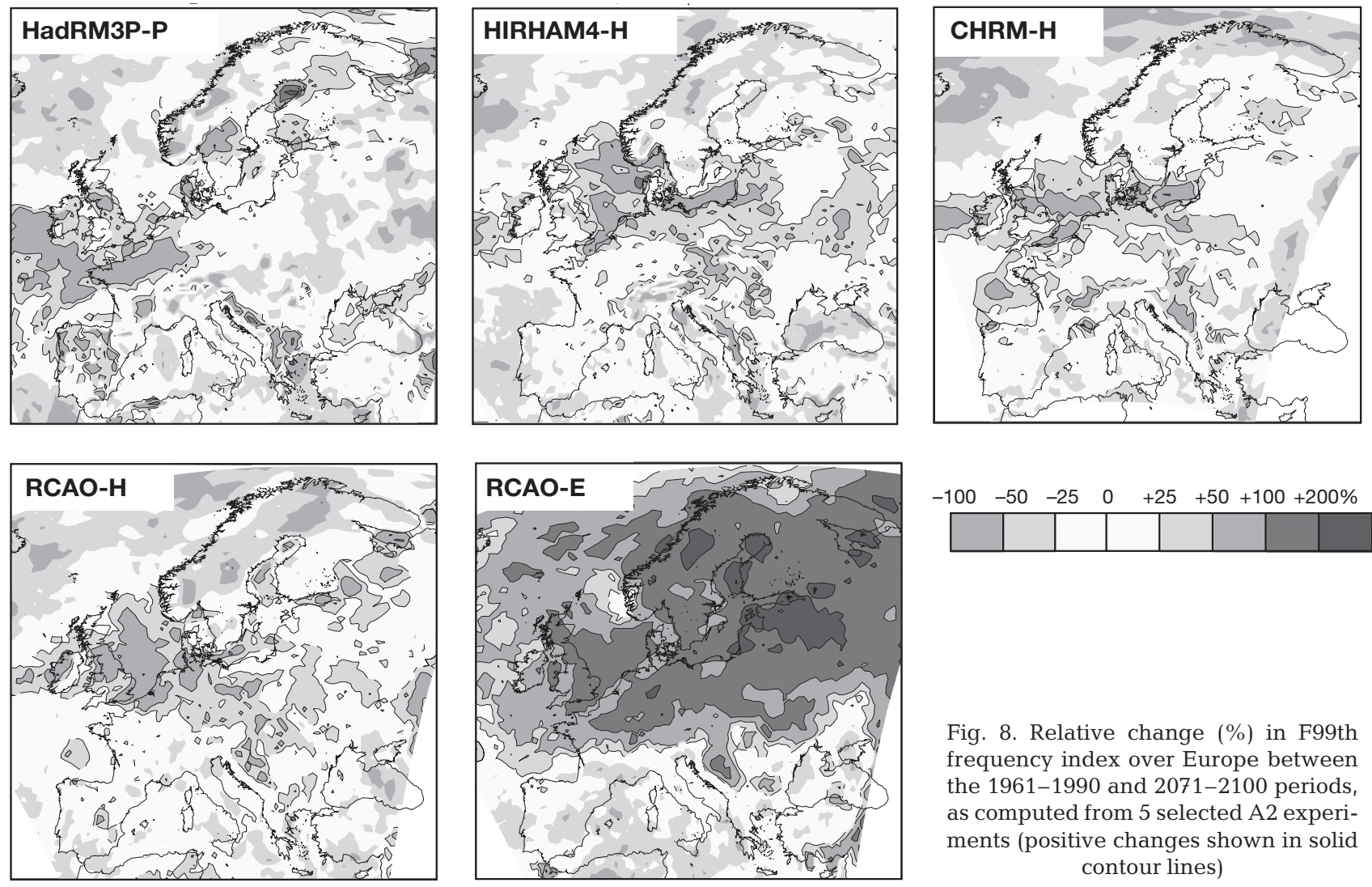

lated only for the DJF months (not shown). For instance, 11 to $17 \%$ of the studied area experiences more than $+4 \%$ of changes in the DJF I99th index for the HadAM3H-driven experiments, compared 5 to $9 \%$ for the ONDJFM 199th index. In the case of the ECHAM-driven experiment, increases above $+8 \%$ in the 199th index are simulated over 14 and $24 \%$ of the domain for the ONDJFM and DJF seasons, respectively.

\subsubsection{Changes in frequency of extreme wind speeds}

In this section, changes in the F90th, F95th and F99th frequency indices of extreme winds, as previously defined in Section 2.2, are investigated on the basis of corresponding 1961-1990 percentile thresholds. Spatial changes in the F99th index over Europe are shown in Fig. 8. They are quite similar to those obtained for changes in the I99th intensity index (Fig. 6). However, they reveal much more pronounced relative changes that are up to or greater than a factor of 2 and 3 for HadAM3H- and ECHAM-driven models, respectively. On the other hand, simulated changes are shown to be statistically significant (positive) over only 8 to 12 and $53 \%$ ( 3 to 6 and $51 \%$ ) of the selected domain for the RCM-H/P and RCM-E experiments, respectively.
Nevertheless, this lower significance compared to changes in the 199th intensity index (21 to 25 and $63 \%$ of positive significant changes, respectively) could be partly due to differences in sample size used for the Mann-Whitney $U$-test $(\mathrm{n}=30$ and 54 data for F99th and I99th indices, respectively).

The RCAO-E model chain predicts positive significant changes over most of Europe, whereas HadAM3H-driven experiments lead to as many negative as positive significant changes. According to these predictions, more than $30 \%$ (RCM-E) or only 0 to $0.4 \%$ (RCM-H/P) of Europe would experience at least twice as many extreme wind days in a future climate scenario. As with intensity, positive changes obtained for DJF only are more pronounced than those obtained for the entire half-year winter period (not shown). Thus, a significant increase (at least by a factor of 2) is predicted over 42 and 1 to $3 \%$ of DJF months, respectively. The RCM-E simulations predict 4 and $13 \%$ of the studied area will experience an increase in the most extreme wind speeds (F99th) by at least a factor of 3 for ONDJFM and DJF, respectively.

Fig. 9 summarizes simulated positive changes in the frequency of extreme wind speeds over Europe between the 20th and 21st century, as a function of the model chain and threshold level (F90th, F95th and F99th frequency indices). As with intensity (Fig. 7), dif- 

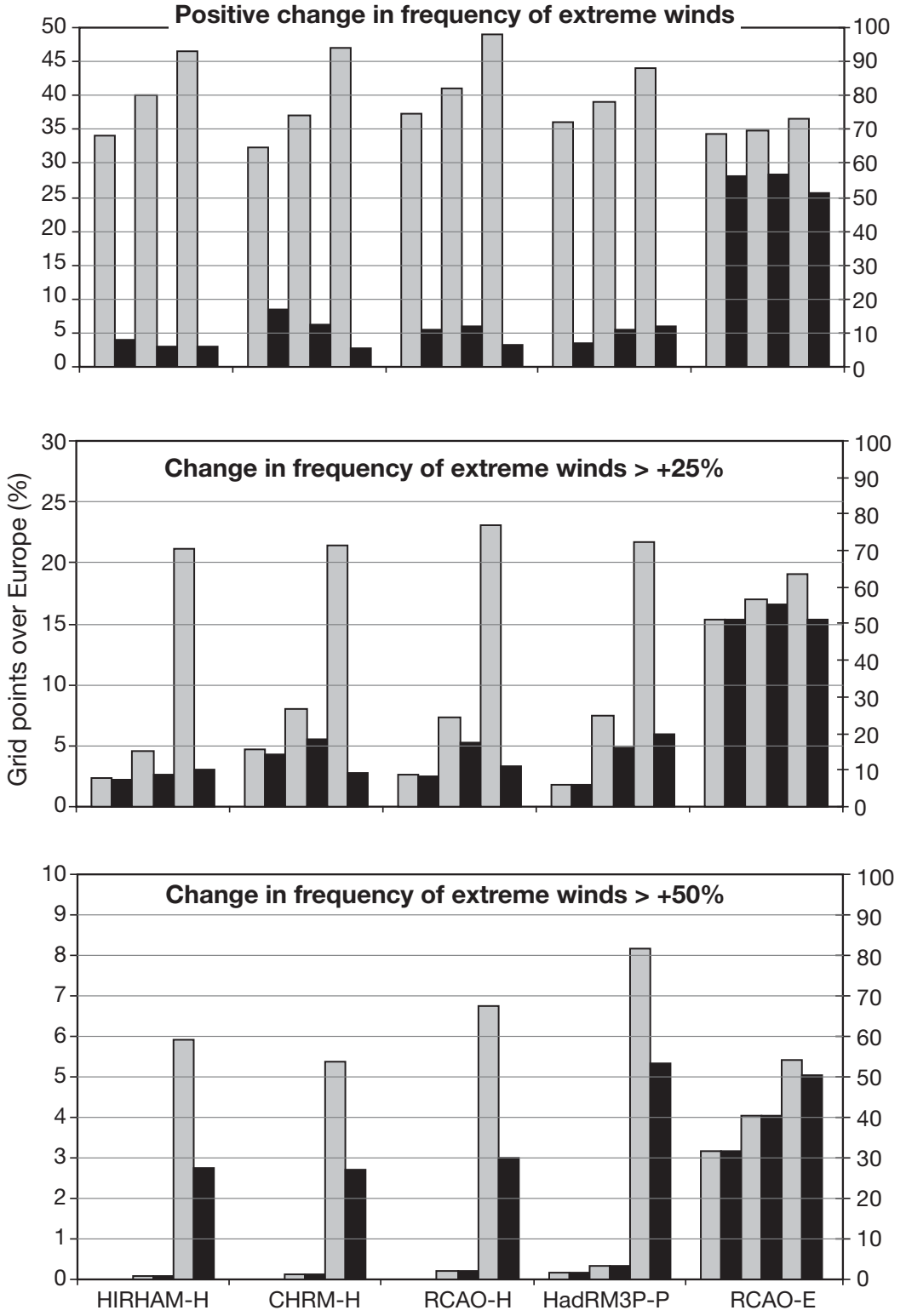

Fig. 9. Proportion (\%) of grid points within the studied European area $\left(35-72^{\circ} \mathrm{N}\right.$, $15^{\circ} \mathrm{W}-43^{\circ} \mathrm{E}$ ) affected by positive changes in (from left to right) F90th, F95th and F99th frequency indices. Grey and black bars correspond to total and to significant (Mann-Whitney unilateral $U$-test, $\alpha<2.5 \%$ ) changes, respectively

ferent scales are used to map RCM-H/P and RCM-E predictions due to large differences in the level of changes. Results for the most pronounced increase in frequency $(>50 \%)$ reveal that the higher the percentile, the higher the change (change in F90th index < change in F95th index < change in F99th index). This non-linearity in the change of the F99th frequency index of extreme wind speeds (also predicted for the I99th intensity index from Hadley Centre-driven experiments) is less pronounced when obtained from RCAO-E simulations.

\subsection{Relationship between extreme wind speeds and related cyclone systems}

Finally, we would like to address the question of changing relationships between extreme wind speeds and related cyclone systems under climate change. For grid points of 3 European regions (British Isles, France, and Germany), days with a daily maximum wind speed above the 95th percentile value were assigned to the core pressure of the nearest identified cyclone. For this part of the study, all identified cyclones were considered in order to minimize potential misleading interpretation due to incorrect linkages between an extreme wind event and the cyclone that caused it. For each region the number of cyclones and its corresponding core pressure are related and presented in terms of the climate change signal (Fig. 10). A remarkable result is that a shift to deeper cyclones that cause extreme wind speeds can be diagnosed. This holds true for all models considered and for all 3 European regions, especially for ETCs with core pressure below $970 \mathrm{hPa}$.

\section{SUMMARY, DISCUSSION AND CONCLUSION}

In this study, 4 different GCMs and related dynamical downscaling model chains (including 5 RCM simulations) were analysed with respect to changing ETC systems and daily maximum wind speeds for the northeast Atlantic/European region. By this multi-model approach, it is possible to address modelinduced variability of potential climate change signals. With respect to ETC identification, the GCMs in question are able to reproduce cyclone track density from a climatological perspective reasonably well. For changed climate conditions (SRES A2 scenario), extreme ETCs behave in a different way to the basic population of cyclone tracks, with partly increasing activity south of $60^{\circ} \mathrm{N}$ over the northeast Atlantic and western parts of central Europe. However, models do not react in a uniform manner. In particular, ECHAM4/OPYC3 reveals a different pattern. Moreover, results obtained from the analysis of climate change signal for dynamical downscaled daily maximum wind speeds with differ- 

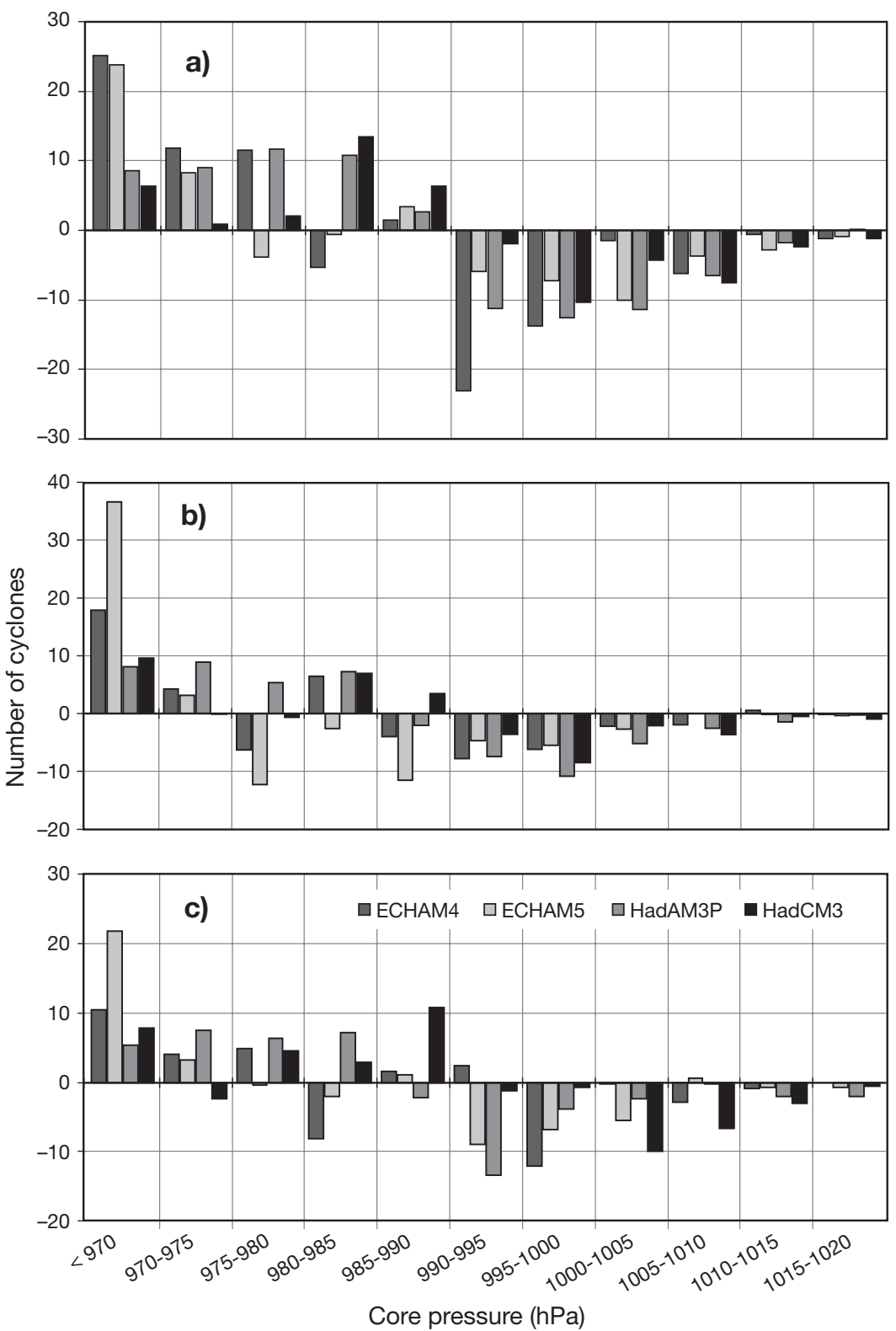

Fig. 10. Climate change signal of cyclone frequency distribution with respect to core pressure $(\mathrm{hPa})$ of nearest cyclone for extreme wind events (i.e. daily maximum $10 \mathrm{~m}$ wind above 95th percentile) for the region. (a) Germany, averaged for: HadAM3P and HadCM3 grid points between $56.25-48.75^{\circ} \mathrm{N}, 5.63-13.13^{\circ} \mathrm{E}$; ECHAM4 and ECHAM5 grid points between $55.00-47.50^{\circ} \mathrm{N}, 7.50-12.50^{\circ} \mathrm{E}$. (b) British Isles, averaged for: HadAM3P and HadCM3 grid points between $58.13-50.63^{\circ} \mathrm{N}, 10.31-0.94^{\circ} \mathrm{E}$; ECHAM4 and ECHAM5 grid points between $57.50-50.00^{\circ} \mathrm{N}, 10.00^{\circ} \mathrm{W}-$ $0.00^{\circ}$ E. (c) France, averaged for: HadAM3P and HadCM3 grid points between $50.63-43.13^{\circ} \mathrm{N}, 4.69^{\circ} \mathrm{W}-6.56^{\circ} \mathrm{E}$; ECHAM4 and ECHAM5 grid points between $50.00-42.50^{\circ} \mathrm{N}, 5.00^{\circ} \mathrm{W}-7.50^{\circ} \mathrm{E}$

ent RCMs are consistent with these findings. Our studies have demonstrated the ability of RCMs to simulate realistic mean distribution patterns of daily mean wind speed over most of Europe, while simulated maximum wind speeds may be locally very different from the reality according to the model under consideration. Indices of relative changes in intensity and frequency of extreme winds, based on percentile thresholds, have therefore been used. This procedure has the advantage of allowing a comparison of wind distributions Europe-wide and also to partly avoid biases due to model discrepancies.

Significant positive changes (from 2 up to $16 \%$ ) in intensity of the most extreme winds (I99th) are predicted over about 20 and $60 \%$ of the European domain from RCM-H/P and RCM-E simulations, respectively. Changes in frequency of extreme winds show similar spatial patterns but much higher relative changes, i.e. by up to more than factors of 2 and 3, respectively, with the strongest winds showing the highest increases. Very different geographical patterns are obtained for the 3 driving GCMs: the most affected area is centred over northwestern Europe in the case of the Hadley Centre model driven experiments, whereas RCAO-E experiment predicts positive changes over the entire northern half of Europe. Similar differing spatial patterns according to the driving GCM have been observed in the PRUDENCE predicted changes in temperature over Europe (e.g. Koffi et al. 2003). On the other hand, if largescale atmospheric circulation is shown to be the main source of uncertainty, there is no major difference between changes as simulated by the different RCMs when driven by the same GCM, the model considers whether or not gust parameterization. Therefore, if this additional refinement in the calculation of the daily maximum wind speed might obviously be useful in terms of impact evaluation of windstorms, it does not appear to provide any spatially refined information on the predicted changes.

In conclusion, even though the models simulate noticeable differences in spatial patterns and levels of changes, all the selected up-todate global and regional climate simulations predict a significant increase in the occurrence of wind extremes over large parts of Europe by the end of the 21st century, with northwestern Europe being likely the most affected area. The occurrence of these extreme wind speeds is linked to cyclones with deeper core pressure and shifted pathways compared to present climate conditions. These results suggest a highly probable increase in damage potentials, e.g. on buildings, which could be enhanced due to the increase in socio-economic expo- 
sure to extreme wind speeds. Further investigations need to be carried out in order to examine how far reasons for the discrepancies are inherent in the specific model, or result from long-term climate variability. On the other hand, the findings from this multi-model analysis confirm the reliability of previous studies (e.g. Leckebusch \& Ulbrich 2004) as well as the changes they predicted under anthropogenically modified climate conditions.

Acknowledgements. This work was supported by the European Union programme Energy, Environment and Sustainable Development under contract EVK2-CT-2001-00132 (PRUDENCE) and EVK2-CT-2001-00118 (MICE). We kindly thank Ole Christensen (Danish Meteorological Institute), Tom Hold, and Matt Livermore (CRU) for providing access to climate model simulations and for related technical support. Homogeneous time series of observed daily maximum wind speed used in this study are part of the French IMFREX project's dataset and have been provided by the Météo-France organization. We acknowledge the international modelling groups for providing their data for analysis, the Program for Climate Model Diagnosis and Intercomparison (PCMDI) for collecting and archiving the model data, the JSC/CLIVAR Working Group on Coupled Modelling (WGCM) and their Coupled Model Intercomparison Project (CMIP) and Climate Simulation Panel for organizing the model data analysis activity, and the IPCC WG1 TSU for technical support. The IPCC Data Archive at Lawrence Livermore National Laboratory is supported by the Office of Science, U.S. Department of Energy. Two anonymous referees are thanked for their comments that helped improve the quality of this manuscript.

\section{LITERATURE CITED}

Carnell RE, Senior CA (1998) Changes in mid-latitude variability due to increasing greenhouse gases and sulphate aerosols. Clim Dyn 14:369-383

Christensen OB, Christensen JH, Machenhauer B, Botzet M (1998) Very high resolution regional climate simulations over Scandinavia-present Climate. J Clim 11:3204-3229

Christensen JH, Carter T, Giorgi F (2002) PRUDENCE employs new methods to assess european climate change. EOS Trans Am Geophys Union 83:147

Cornford SG (2002) Human and economic impacts of weather events in 2001. WMO Bull 51:257-277

Déqué M (2004) Uncertainties in PRUDENCE simulations: global high resolution models. Available at http://prudence. dmi.dk/public/publications/D1A5.pdf

Dorland C, Tol RSJ, Olsthoorn AJ, Palutikof JP (1999) Impacts of windstorms in the Netherlands: present risk and prospects for climate change. In: Downing TE, Olsthoorn AJ, Tol RSJ (eds) Climate, change and risk. Routledge, London, p 245-278

Fink AH, Brücher T, Leckebusch GC, Krüger A, Pinto JG, Ulbrich U (2004) The 2003 European summer heatwaves and drought-synoptic diagnosis and impacts. Weather 59:209-216

Geng Q, Sugi M (2003) Possible change of extratropical cyclone activity due to enhanced greenhouse gases and sulfate aerosols - study with a high-resolution AGCM. J Clim 16:2262-2274

Gordon C, Cooper C, Senior CA, Banks HT, Gregory JM, Johns TC, Mitchell JFB, Wood RA (2000) The simulation of
SST, sea ice extents and ocean heat transports in a version of the Hadley Centre coupled model without flux adjustment. Clim Dyn 16:147-168

Hudson DA, Jones RG (2002) Simulations of present-day and future climate over southern Africa using HadAM3H. Hadley Centre Tech Note no. 38. Hadley Centre for Climate Prediction and Research, Met Office, Bracknell

Johns TC, Gregory JM, Ingram WJ, Johnson CE and 8 others (2003) Anthropogenic climate change for 1860 to 2100 simulated with the HadCM3 model under updated emissions scenarios. Clim Dyn 20:583-612

Jones PD, Horton EB, Folland CK, Hulme M, Parker DE, Basnett TA (1999) The use of indices to identify changes in climatic extremes. Clim Change 42:131-149

Jones A, Roberts DL, Woodage MJ, Johnson CE (2001) Indirect sulphate aerosol forcing in a climate model with an interactive sulphur cycle. J Geophys Res 106:20293-20310

Jungo P, Goyette S, Beniston M (2002) Daily wind gust speed probabilities over Switzerland according to three types of synoptic circulation. Int J Clim 22:485-499

Kalnay E, Kanamitsu M, Kistler R, Collins W and 18 others (1996) The NCEP-NCAR 40-year reanalysis project. Bull Am Meteorol Soc 77:437-472

Kharin VV, Zwiers FW (2000) Changes in the extremes in an ensemble of transient climate simulations with a coupled atmosphere-ocean GCM. J Clim 13:3760-3780

Knippertz P, Ulbrich U, Speth P (2000) Changing cyclones and surface wind speeds over the North Atlantic and Europe in a transient GHG experiment. Clim Res 15: 109-122

Koffi B, Goyette S, Beniston M (2003) Heatwaves and wind storms in a changing climate. Geophys Res Abstracts, Vol 5. EAE03-A-02655, ISSN: 1029-7006, 2003

Lambert SJ (1996) Intense extra-topical Northern Hemisphere winter cyclone events: 1189-1991. J Geophys Res 101:21319-21325

Leckebusch GC, Ulbrich U (2004) On the relationship between cyclones and extreme windstorm events over Europe under climate change. Global Planet Change 44: 181-193

Lunkeit F, Ponater M, Sausen R, Sogalla M, Ulbrich U, Windelband M (1996) Cyclonic activity in a warmer climate. Contrib Atmos Phys 69:393-407

Lüthi D, Cress A, Davies HC, Frei C, Schär C (1996) Interannual variability and regional climate simulations. Theor Appl Climatol 53:185-209

McAvaney BJ, Covey C, Joussaume S, Kattsov V and 69 others (2001) Model evaluation. In: Houghton JT, Ding Y, Griggs DJ, Noguer M, van der Linden PJ, Dai X, Maskell K, Johnson CA (eds) IPCC TAR climate change, 2001: Working Group I: the scientific basis. Cambridge University Press, Cambridge, p 471-524

McCabe GJ, Clark MP, Serreze MC (2001) Trends in northern hemisphere surface cyclone frequency and intensity. J Clim 14:2763-2768

Meehl GA, Tebaldi C (2004) More intense, more frequent, and longer lasting heat waves in the 21st century. Science 305:994-997

Murray RJ, Simmonds I (1991) A numerical scheme for tracking cyclone centres from digital data. Part I: development and operation of the scheme. Aust Met Mag 39:155-166

Nakićenović N, Alcamo J, Davis G, de Vries B and 24 others (2000) Emission scenarios. A special report of Working Group III of the Intergovernmental Panel on Climate Change. Cambridge University Press, Cambridge

New M, Hulme M, Jones P (1999) Representing twentiethcentury space-time climate variability. Part I: development 
of a 1961-90 mean monthly terrestrial climatology. J Clim 12:829-856

Paciorek JC, Risbey JS, Ventura V, Rosen RD (2002) Multiple indices of Northern Hemisphere cyclonic activity, Winters 1949-99. J Clim 15:1573-1590

Peterson TC, Folland C, Gruza G, Hogg W, Mokssit A, Plummer N (2001) Report on the activities of the Working Group on Climate Change Detection and Related Rapporteurs, 1998-2001. Rep WCDMP-47, WMO-TD 1071. World Meteorological Organisation, Geneva

Pinto JG (2002) Influence of large-scale atmospheric circulation and baroclinic waves on the variability of mediterranean rainfall. $\mathrm{PhD}$ dissertation, University of Cologne

Pinto JG, Spangehl T, Ulbrich U, Speth P (2005) Sensitivities of a cyclone detection and tracking algorithm: individual tracks and climatology. Meteorol Z 14:823-838

Pinto JG, Spangehl T, Ulbrich U, Speth P (2006) Assessment of winter cyclone activity in a transient ECHAM4-OPYC3 GHG experiment. Meteorol Z 15(3):1-13

Räisänen J, Hansson U, Ullerstig A, Döscher R and 5 others (2004) European climate in the late 21st century: regional simulations with two driving global models and two forcing scenarios. Clim Dyn 22:13-31

Roeckner E, Bengtsson L, Feichter J, Lelieveld J, Rodhe H (1999) Transient climate change simulations with a coupled atmosphere-ocean GCM including the tropospheric sulfur cycle. J Clim 12:3004-3032

Roeckner E, Bäuml G, Bonaventura L, Brokopf R and 10

Submitted: May 18, 2005; Accepted: February 25, 2006 others (2003) The atmospheric general circulation model ECHAM 5. Part I: model description. Max-Planck-Institut für Meteorologie, Hamburg, MPI-Rep 349

Roeckner E, Brokopf R, Esch M, Giorgetta M and 5 others (2004) The atmospheric general circulation model ECHAM5. Part II: sensitivity of simulated climate to horizontal and vertical resolution. Max-Planck-Institut für Meteorologie, Hamburg, MPI-Rep 354

Schrodin R (1995) Dokumentation des EM/DM-Systems. Deutscher Wetterdienst/Abteilung Forschung, Offenbach am Main

Serreze MC, Carse F, Barry RG (1997) Icelandic low cyclone activity climatological features, linkages with the NAO, and relationships with recent changes in the Northern Hemisphere circulation. J Clim 10:453-464

Simmonds I, Keay K (2000) Variability of Southern Hemisphere extra-tropical cyclone behaviour, 1958-97. J Clim 13:550-561

Ulbrich U, Brücher T, Fink AH, Leckebusch GC, Krüger A, Pinto JG (2003a) The central European floods of August 2002. Part I: rainfall periods and flood development. Weather 58:371-377

Ulbrich U, Brücher T, Fink AH, Leckebusch GC, Krüger A, Pinto JG (2003b) The central European floods of August 2002. Part II: synoptic causes and considerations with respect to climatic change. Weather 58:434-442

Vidale PL, Lüthi D, Frei C, Seneviratne S, Schär C (2003) Predictability and uncertainty in a regional climate model. J Geophys Res 108:4586, doi 10.1029/2002JD002810

Proofs received from author(s): June 9, 2006 